\title{
Analyses of Genetic Variations of Glutathione S-Transferase Mul and Thetal Genes in Bangladeshi Tannery Workers and Healthy Controls
}

\author{
Jobaida Akther, ${ }^{1}$ Akio Ebihara, ${ }^{2}$ Tsutomu Nakagawa, ${ }^{2}$ Laila N. Islam, ${ }^{1}$ Fumiaki Suzuki, ${ }^{2}$ \\ Md. Ismail Hosen, ${ }^{1}$ Mahmud Hossain, ${ }^{1}$ and A. H. M. Nurun Nabi ${ }^{1}$ \\ ${ }^{1}$ Department of Biochemistry and Molecular Biology, University of Dhaka, Dhaka 1000, Bangladesh \\ ${ }^{2}$ Laboratory of Applied Biochemistry, Faculty of Applied Biological Sciences, Gifu University, 1-1 Yanagido, Gifu 501-1193, Japan
}

Correspondence should be addressed to A. H. M. Nurun Nabi; nabi@du.ac.bd

Received 9 February 2016; Accepted 5 April 2016

Academic Editor: Christian Guelly

Copyright (C) 2016 Jobaida Akther et al. This is an open access article distributed under the Creative Commons Attribution License, which permits unrestricted use, distribution, and reproduction in any medium, provided the original work is properly cited.

Glutathione S-transferases (GSTs) belong to a group of multigene detoxification enzymes, which defend cells against oxidative stress. Tannery workers are at risk of oxidative damage that is usually detoxified by GSTs. This study investigated the genotypic frequencies of GST Mul (GSTM1) and GST Thetal (GSTT1) in Bangladeshi tannery workers and healthy controls followed by their status of oxidative stress and total GST activity. Of the 188 individuals, 50.0\% had both GSTM1 and GSTT1 (+/+), 12.2\% had GSTM1 $(+/-), 31.4 \%$ had GSTT1 (-/+) alleles, and 6.4\% had null genotypes (-/-) with respect to both GSTM1 and GSTT1 alleles. Among 109 healthy controls, $54.1 \%$ were double positive, 9.2\% had GSTM1 allele, 32.1\% had GSTT1 allele, and 4.6\% had null genotypes. Out of 79 tannery workers, $44.3 \%$ were $+/+, 16.8 \%$ were $+/-, 30.5 \%$ were $-/+$, and $8.4 \%$ were $-/-$. Though the polymorphic genotypes or allelic variants of GSTM1 and GSTT1 were distributed among the study subjects with different frequencies, the differences between the study groups were not statistically significant. GST activity did not vary significantly between the two groups and also among different genotypes while level of lipid peroxidation was significantly higher in tannery workers compared to controls irrespective of their GST genotypes.

\section{Introduction}

Glutathione transferases (GSTs) protect cells against electrophiles and products of oxidative stress by catalyzing nucleophilic attack of the tripeptide thiol, glutathione on different reactive electrophiles, which otherwise are potentially toxic and can bind to proteins and DNA to cause cellular damage or genetic mutation [1]. These enzymes help to detoxify the compounds, increase their water solubility, and facilitate excretion through urine. In human, a significant number of genetic polymorphisms among the GST enzymes have been described [2]. Individual differences in GST activity are the result of genetic polymorphism of these enzymes. Out of the two GSTs in human, membrane bound GSTs represent 45 of the total proteins present in endoplasmic reticulum and the outer mitochondria while the cytosolic GSTs account for $10 \%$ of total cellular proteins [3]. The cytosolic family is further divided into seven classes: Alpha, Mu, Omega, Pi, Sigma, Theta, and Zeta. The Alpha, Mu, and Theta GST classes each contain multiple isoenzymes. One of these genes, GSTM1, encodes for a class $\mu$ GST isoenzyme involved in polycyclic aromatic hydrocarbons (PAHs) detoxification. Three alleles exist at the locus for human GSTM1, namely, GSTM1*A, GSTM1 ${ }^{*} \mathrm{~B}$, and GSTM1 ${ }^{*} 0$, the latter corresponding to an entire gene deletion [4]. About $50 \%$ of the individuals in most Caucasian populations are GSTM $1{ }^{*} 0 / \mathrm{GSTM}^{*} 0$ homozygous and lack $\mu$ GST isoenzyme activity. This has been reported to be possibly associated with an increased susceptibility to different types of cancer including bronchogenic carcinoma [5], urinary bladder cancer [6], and multiple skin tumours [7].

Another polymorphic gene of the same family is GSTT1 which encodes for a class $\theta$ GST that catalyzes the conjugation of halomethanes in human erythrocytes [8]. Substrates of 
$\theta$ GST include industrial chemicals such as methyl chloride, methyl bromide, dichloromethane, ethylene oxide, and diepoxybutane, a reactive metabolite of 1,3-butadiene. Individuals with homozygous GSTT1 gene deletion (GSTT1*0) show a functional deficiency in Theta GST activity in erythrocytes [9]. The prevalence of the GSTT1 $* 0$ genotype has been shown to vary between different ethnic groups ranging from 20 to $26 \%$ in a group of South Africans to $58 \%$ among a group of Chinese people $[10,11]$. Some differences have even been found within Caucasian populations [12]. Few reports have linked the homozygous GSTT1*0 genotype to increased cancer susceptibility, but an increased prevalence of the combined GSTM1 and GSTT1 null genotypes has been found among head and neck cancer patients [13]. The GSTT1 null genotype has also been found to influence the age of onset of colon cancer [14].

Workers in the tannery industries directly and inhabitants living around indirectly are at risk of severe health problems due to contamination of drinking water through percolation of untreated or incompletely treated effluents into the ground [15]. Besides, the toxicity can be mediated through inhalation and absorption via skin. Employees of these industries are exposed to higher than normal chromium [16] in the form of either organic chromium or chromium bound to protein (leather dust). Though all organisms have evolved protective mechanisms and programmed responses to limit cellular damage from exposure to toxic compounds in their environment, heavy metals are reported to disturb reactive oxygen neutralizing enzymes and their intoxication causes neurotoxicity, genotoxicity, or carcinogenicity [17]. Gene polymorphism is one of the genetic susceptibility factors that influence the level of DNA damage by affecting the individual's metabolism and repair of various DNA lesions induced by reactive components. For achieving the aim of the present study, allele specific polymerase chain reaction was employed to (i) investigate the distribution of genotypic frequencies of glutathione S-transferase Mul (GSTM1) and Thetal (GSTT1) genes in Bangladeshi tannery workers and healthy controls, (ii) determine the distribution of total GST activity in the plasma of different genotypes among the studied subjects, and (iii) evaluate the level of lipid peroxidation (a marker of oxidative stress) in the plasma of the studied subjects.

\section{Material and Methods}

2.1. Rationale of Choosing GSTM1 and GSTT1 out of the Seven Classes of GST Enzymes. Due to the presence of many polymorphisms in GST genes, considerable attention has been bestowed in determining the association of particular allelic variants with the outcome of a variety of diseases. Among all the enzymes of GST family, two major deletion polymorphisms in GSTM1 and GSTT1 genes have shown clinical significance. These deletions result in the absence of enzyme activity, specifically in individuals with null genotypes (absence of both genes due to deletions). The null genotype (GSTM1/GSTT1, -/-) has been associated with altered risk of a variety of pathologies including cancer, cardiovascular disease, respiratory diseases [18-20], and ophthalmologic problems such as cataract [21] and senile macular degeneration [22].

2.2. Subject Selection, Sample Collection, and Extraction of Genomic DNA. A total of 190 Bangladeshi people not related to each other were enrolled in this study. Among them, 81 were tannery workers and 109 were healthy control subjects. Before enrolling in the study, each individual was informed about the viewpoint of the study and, after getting their full consent, they were included in the present study and blood samples were collected. Individuals with hypertension and cardiovascular disease related complications, diabetes, chronic kidney disease, or any other major renal diseases and being hepatitis B virus surface antigen (HbsAg) positive were excluded from this study. Healthy control subjects were nontannery workers, randomly selected from the homogeneous ethnic background as of the tannery workers. During interview session, two of the tannery workers were found to be suffering from diabetes and high blood pressure. Thus, finally blood samples from 79 tannery workers were analyzed for the study. All the subjects were also interviewed according to the structured questionnaire and the data were recorded. The study was approved by the Ethical Review Board of the Faculty of Biological Sciences, University of Dhaka, Bangladesh. Five milliliters of blood was collected from each individual in EDTA containing vacutainer tubes by the help of an expert phlebotomist in the presence of the concerned physician. Genomic DNA was extracted and quantity and quality of the extracted DNA were verified according to our previous method [23].

2.3. Analyses of GSTM1 and GSTT1 Polymorphisms. GSTM1 and GSTT1 genes were amplified by allele specific polymerase chain reaction (PCR). Primer sequences for GSTM1 were $5^{\prime}$-GAACTCCCTGAAAAGCTAAAGC-3' (forward primer) and $5^{\prime}$-GTTGGGCTCAAATATACGGTGG-3' (reverse primer), which produced a 219-base pair PCR product. The GSTT1 primers were $5^{\prime}$-TTCCTTACTGGTCCTCACATCTC-3' (forward primer) and $5^{\prime}$-TCACCGGATCATGGCCAGCA-3' (reverse primer), which produced a 480 -base pair PCR product. In the same PCR reactions, $\beta$-globin (268-base pair) was amplified with the primers $5^{\prime}$-CAACTTCATCCACGTTCACC-3' (forward primer) and $5^{\prime}$-GAAGAGCCAAGGACAGTTAC-3' (reverse primer) as an internal control of DNA sample. The PCR was performed under the following conditions: 10 minutes of denaturation at $95^{\circ} \mathrm{C}$ followed by 40 cycles of 1 minute at $95^{\circ} \mathrm{C}, 1$ minute at $56^{\circ} \mathrm{C}, 1$ minute at $72^{\circ} \mathrm{C}$, and a final extension for 10 minutes at $72^{\circ} \mathrm{C}$. The amplification products were separated on $2 \%$ agarose gels, stained with ethidium bromide for the analyses of genotypes, and only those PCR signals were considered in which the corresponding $\beta$-globin gene internal control was apparent.

\subsection{Measurement of the Activity of Plasma Glutathione S-} Transferase. Glutathione S-transferase activity was measured according to the method described by Mannervik and Guthenberg [24]. The reaction was carried out in duplicate 
TABLE 1: Anthropometric data of healthy control subjects and tannery workers.

\begin{tabular}{lccc}
\hline Parameters & Total study subjects $(n=129)$ & Control subjects $(n=50)$ & Tannery workers $(n=79)$ \\
\hline BMI $\left(\mathrm{kg} / \mathrm{m}^{2}\right)$ & $23.1 \pm 3.21$ & $24.3 \pm 3.34$ & $21.9 \pm 3.09$ \\
& $(14.57-31.07)$ & $(14.57-31.07)$ & $(15.7-29.7)$ \\
Age (years) & $30.95 \pm 6.76$ & $28.0 \pm 2.0$ & $33.9 \pm 11.5$ \\
& $(15-55)$ & $(19-42)$ & $(15-55)$ \\
SBP (mmHg) & $122.38 \pm 13.35$ & $126.30 \pm 15.41$ & $(110-130)$ \\
& $(100-160)$ & $81.73 \pm 8.80$ & $(100-160)$ \\
DBP (mmHg) & $79.52 \pm 7.7$ & $(78-88)$ & $77.31 \pm 6.60$ \\
Smoking habit (\%) & $(75-90)$ & 20 & $(70-90)$ \\
\hline
\end{tabular}

$n=$ number of individuals; numerical values in the parentheses indicate ranges of respective parameters.

by observing the conjugation of 1-chloro-2,4-dinitrobenzene (CDNB) with reduced glutathione (GSH). This was done by observing an increase in absorbance at $340 \mathrm{~nm}$. One unit of enzyme will conjugate $10.0 \mathrm{nmol}$ of $\mathrm{CDNB}$ with reduced glutathione per minute at $25^{\circ} \mathrm{C}$. The results were expressed as $\mathrm{U} / \mathrm{L}$.

\subsection{Determination of the Values of Thiobarbituric Acid React-} ive Substances. Thiobarbituric acid reactive substances (TBARS) value was determined according to the method of Yagi [25]. Two $\mathrm{mL}$ of working TBA reagent was added to $1 \mathrm{~mL}$ sample $(100 \mu \mathrm{L}$ serum $+900 \mu \mathrm{L}$ saline $)$, followed by the addition of $30 \mu \mathrm{L}$ of $50 \mathrm{mM}$ butylated hydroxytoluene (BHT). The mixture was incubated for 15 minutes in a boiling water bath. It was then kept in ice bath for 15 minutes. Above steps were repeated for the standards. Then, the sample tubes were centrifuged for 10 minutes at $2000 \mathrm{rpm}$. Finally, the supernatant was collected to measure the absorbance at $535 \mathrm{~nm}$.

2.6. Statistical Analyses. The results were expressed as mean $( \pm \mathrm{SD})$ and, to compare the differences between different variables from the control and tannery workers, independent Student's $t$-test was performed. A $p$ value of less than 0.05 was considered significant. The GSTM1 and GSTTI genotype frequencies were obtained by direct counting. Statistical analyses between different genotypic subgroups of tannery workers and healthy controls were performed using paired sample $t$-tests.

\section{Results}

3.1. Anthropometric Data of Healthy Controls and Tannery Workers. The average age and BMI $\left(\mathrm{kg} / \mathrm{m}^{2}\right)$ of the total study subjects were $30.95 \pm 6.76$ years and $23.1 \pm 3.21$, respectively. The data showed that $54.4 \%$ of tannery workers had primary education, $30.4 \%$ had secondary education, $12.7 \%$ had no education, and only $2.53 \%$ had higher education. On the other hand, all the healthy controls were well educated. More than $30 \%$ of the total populations were smokers. Their mean systolic blood pressure and diastolic blood pressure were $122.38 \pm 13.35$ and $79.52 \pm 7.7 \mathrm{mmHg}$, respectively. The mean age of the healthy controls was $28.0 \pm 2.0$ years. Their average BMI $\left(\mathrm{kg} / \mathrm{m}^{2}\right)$ was $24.3 \pm 3.34$. The mean systolic and diastolic blood pressure of the control subjects were $126.30 \pm 15.41$ and $81.73 \pm 8.80 \mathrm{mmHg}$, respectively. Twenty percent of them were smokers. A total of 79 workers were included in this study among whom 72 were males and 7 were females. The mean age of tannery workers was $33.90 \pm 11.50$ years. Their average BMI $\left(\mathrm{kg} / \mathrm{m}^{2}\right)$ was $21.90 \pm 3.09$. The mean systolic and diastolic blood pressure of the tannery workers were $118.46 \pm 11.29$ and $77.31 \pm 6.60 \mathrm{mmHg}$, respectively. Detailed anthropometric parameters have been presented in Table 1 . Among the tannery workers, $40.5 \%$ were smokers and $59.5 \%$ were nonsmokers. As only 7 female tannery workers participated in this study, the parameters were not shown separately for males and females.

The average duration of work of the tannery workers was $13.65 \pm 8.16$ years ranging from 5 months to 30 years while their average working hour was $10.6 \pm 2.8$ hours ranging from 8 to 20 hours. Out of these total tannery workers, $6.33 \%$ had pain in the body, $5.1 \%$ had cough, $5.1 \%$ had breathing problem, 3.8\% had headache, and $5.1 \%$ of the workers were suffering from weakness. Most of the workers (94.1\%) had clear chest sound while $5.1 \%$ had noisy sound in their chests. On the other hand, when healthy control subjects were interviewed no such complications were reported.

3.2. Frequency Analyses of Polymorphism of Glutathione S-Transferase M1 and Glutathione S-Transferase T1 Genes in Healthy Controls and Tannery Workers. Amplified PCR products were evaluated by agarose gel electrophoresis using a $2 \%$ agarose gel and visualized under ultraviolet light after ethidium bromide staining using gel picture analyzer (Alpha Analyzer, US). Figure 1 represents the GSTM1 and GSTT1 gene polymorphisms by showing different genotypes. $\beta$ globin gene was used as a positive marker. Sizes of the bands were $219 \mathrm{bp}, 268 \mathrm{bp}$, and $480 \mathrm{bp}$ for GSTM1, $\beta$-globin, and GSTT1, respectively.

Out of the total study subjects, 94 individuals (50.0\%) had both GSTM1 and GSTT1 alleles $(+/+)$ while 23 individuals $(12.2 \%)$ had GSTM1 allele with null GSTT1 allele (+/-) and 59 individuals (31.4\%) had no GSTM1 allele with the presence of GSTT1 allele $(-/+)$. Further, 6.4\% $(n=12)$ of the total individuals were null genotypes for both GSTM1 and GSTT1 genes (-/-). Among 109 healthy controls, 54.1\% 
TABLE 2: Genotype distribution of GSTM1 and GSTT1 alleles in both healthy controls and tannery workers.

\begin{tabular}{lcccc}
\hline Study subjects & $\begin{array}{c}\text { GSTM1/GSTT1 } \\
(+/+), \%\end{array}$ & $\begin{array}{c}\text { GSTM1/GSTT1 } \\
(+/-), \%\end{array}$ & $\begin{array}{c}\text { GSTM1/GSTT1 } \\
(-/+), \%\end{array}$ & $\begin{array}{c}\text { GSTM1/GSTT1 } \\
(-/-), \%\end{array}$ \\
\hline Total & 50.0 & 12.2 & 31.4 & $n .4$ \\
$n=188$ & $n=94$ & $n=23$ & $n=59$ & $n=12$ \\
Healthy controls & 54.1 & 9.2 & 32.1 & $n .6$ \\
$n=109$ & $n=59$ & $n=10$ & $n=35$ & $n=5$ \\
Tannery workers & 44.3 & 16.8 & 30.5 & 8.4 \\
$n=79$ & $n=35$ & $n=13$ & $n=24$ & $n=7$ \\
\hline
\end{tabular}

$n=$ number of individuals. +/+ indicates presence of both GSTM1 and GSTT1 alleles; +/- indicates presence of GSTM1 and absence of GSTT1 alleles (GSTT1 null genotypes); -/+ indicates absence of GSTM1 and presence of GSTT1 alleles (GSTM1 null genotypes); -/- indicates absence of both GSTM1 and GSTT1 alleles.

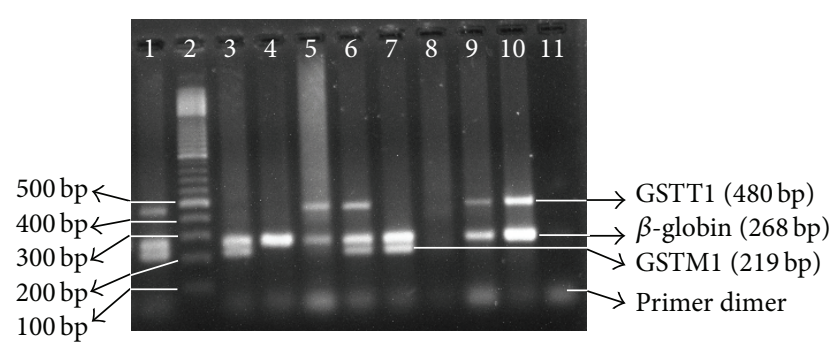

Figure 1: Agarose gel electrophoresis showing the genotypes of GSTM1 and GSTT1 genes. The presence or absence of GSTM1 and GSTT1 genes was detected by the presence of a band at $219 \mathrm{bp}$ (corresponding to GSTM1) and a band at $480 \mathrm{bp}$ (corresponding to GSTT1). The bands at lane 2 indicate molecular marker of $100 \mathrm{bp}$ DNA ladder. A band at 268 bp (corresponding to $\beta$-globin gene) was always present and was used as internal control to document successful PCR amplification. Lanes 1 and 6 indicate individuals with the presence of both GSTM1 and GSTT1 alleles (+/+). Lane 4 represents an individual with null alleles for both GSTM1 and GSTT1 genes ( $(-)$ ) showing only one band at 268 bp corresponding to the internal control ( $\beta$-globin gene fragment). Lanes 3 and 7 represent presence of GSTM1 allele and absence of GSTT1 allele (GSTT1 null allele, $+/-$ ). Lane 8 is negative control. Lanes 9 and 10 correspond to the individuals with GSTM1 null and GSTT1 present (480 bp) alleles $(-/+)$. The bands at the bottom of the gel are due to the formation of dimer by the primers.

had both GSTM1 and GSTT1 allele, 9.2\% had GSTM1 allele with no GSTT1 allele, $32.1 \%$ had GSTT1 allele with no allele for GSTM1 gene, and 4.6\% individuals represented null genotype. Out of the total 79 tannery workers, $43.3 \%$ had both GSTM1 and GSTT1 allele, 16.5\% had GSTM1 allele with no allele for GSTT1 gene, 30.4\% had GSTT1 allele with no GSTM1 allele, and $8.9 \%$ of the total workers represented null genotypes for both GSTM1 and GSTT1 genes. Frequency analyses of the GSTM1 and GSTT1 genotypes have been presented in Table 2.

\subsection{Glutathione S-Transferase Activity in the Total Participants} and Its Genotypic Distribution. The mean activity of GST was estimated to be $1.73 \pm 0.35 \mathrm{U} / \mathrm{L}$ in the plasma of healthy controls, while this value in the plasma of tannery workers was measured to be $1.88 \pm 0.59 \mathrm{U} / \mathrm{L}$. Statistical analysis using

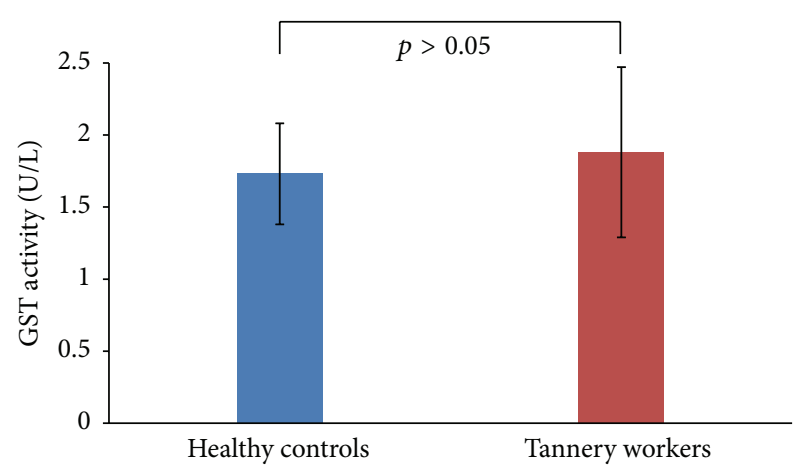

FIGURE 2: GST activity in the plasma of healthy controls and tannery workers. Though GST activity (U/L) in the plasma of tannery workers was higher compared to that of the control subjects, it did not vary significantly $(p=0.071)$.

independent sample $t$-test revealed that the GST activity between these two groups is not significant $(p=0.071)$ as shown in Figure 2. However, the average GST activities in the smokers and nonsmokers within the tannery workers were $1.92 \pm 0.71$ and $1.86 \pm 0.51$, respectively $(p>0.05)$.

Out of the total study subjects, the mean activity of GST in the individuals with both GSTM1 and GSTT1 alleles was $1.92 \pm 0.61 \mathrm{U} / \mathrm{L}$, in individuals having GSTM1 allele with null GSTT1 allele it was $1.81 \pm 0.43 \mathrm{U} / \mathrm{L}$, in individuals having GSTT1 allele with null of GSTM1 allele it was $1.66 \pm 0.4 \mathrm{U} / \mathrm{L}$, and in individuals with both null genotypes for GSTM1 and GSTT1 genes it was $1.11 \pm 0.46 \mathrm{U} / \mathrm{L}$. Tannery workers with both alleles for GSTM1 and GSTT1 genes and double null genotypes (-/-) had higher activity of plasma GST $(2.05 \pm 0.71$ and $1.95 \pm 0.48 \mathrm{U} / \mathrm{L})$ compared to their healthy counterparts $(1.74 \pm 0.38$ and $1.54 \pm 0.25 \mathrm{U} / \mathrm{L}$, resp.). On the other hand, the plasma GST activities in the individuals either having GSTM1 allele with null allele for GSTT1 gene or having GSTT1 allele with null allele for GSTM1 gene were almost similar to those in the plasma of healthy controls $(1.78 \pm 0.3$ versus $1.87 \pm 0.27 \mathrm{U} / \mathrm{L}$ and $1.67 \pm 0.47$ versus $1.67 \pm 0.35 \mathrm{U} / \mathrm{L}$, resp.). Statistical analyses revealed that the variations of GST activities in the plasma of tannery workers with different genotypes were not significant. Distributions of GST activities in different genotypic groups of study subjects have been presented in Figure 3. 


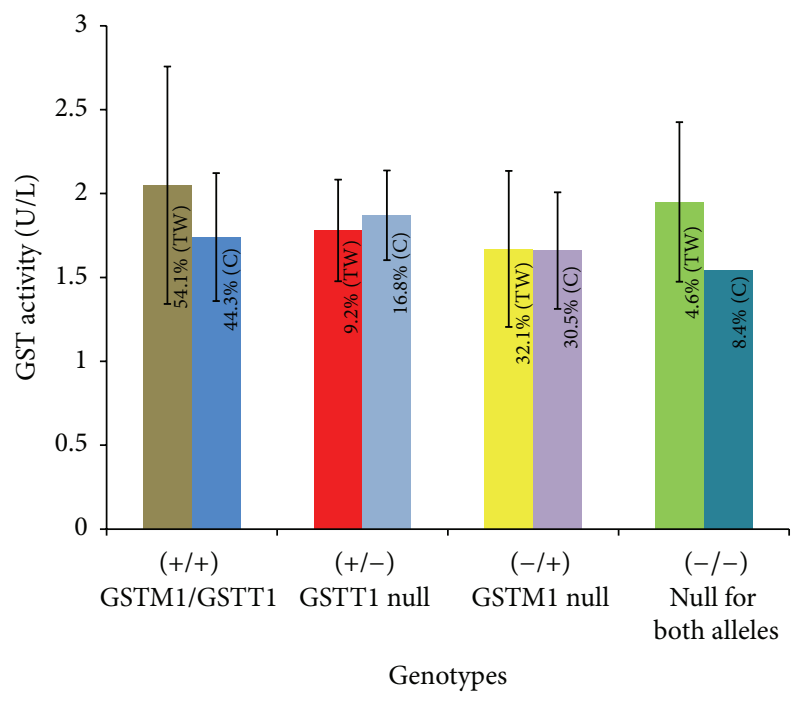

FIGURE 3: Distribution of GST activity in different genotypes of tannery workers (TW) and healthy controls (C). GST activity varied in different genotypes. The activity was found higher in individuals having both the alleles for GSTM1 and GSTT1 genes. On the other hand, GST activity was found lower in individuals having allele for either GSTM1 or GSTT1 gene (+/-, GSTT1 null genotypes; -/+, GSTTM1 null genotypes). Interestingly, GST activity was also found higher in individuals with null alleles (-/-) for both the GSTM1 and GSTT1 genes. The bars represent the standard deviation of GST activities of each genotype and the GST activities (expressed as U/L) were calculated from the average of two independent experiments for each sample. Values within the bar represent the percentages of respective genotypes in the studied population.

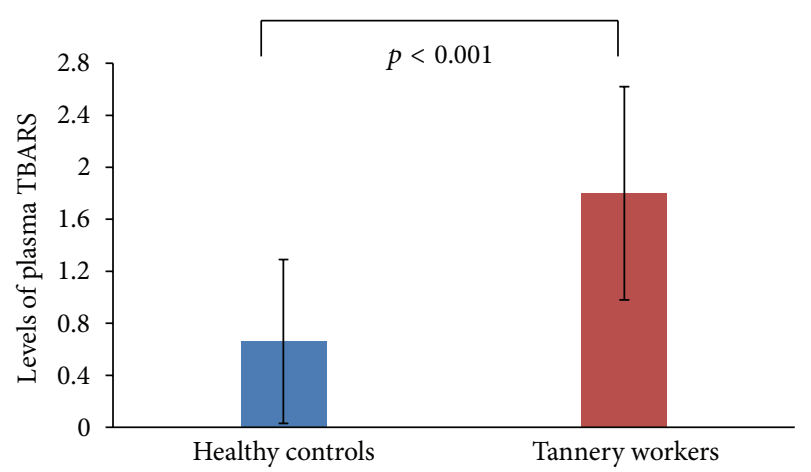

FIGURE 4: TBARS value in the plasma of healthy controls and tannery workers. Statistical analysis revealed that the level of TBARS was significantly higher $(p<0.0001)$ in tannery workers $(1.80 \pm$ $0.82 \mathrm{nmol} / \mathrm{mL})$ than the healthy controls $(0.66 \pm 0.63 \mathrm{nmol} / \mathrm{mL})$.

3.4. Levels of TBARS in the Plasma of Total Participants and Their Genotypic Distribution. The mean level of TBARS in the plasma of the total tannery workers was $1.80 \pm 0.82 \mathrm{nmol} /$ $\mathrm{mL}$ while in the plasma of the healthy controls it was found to be $0.66 \pm 0.63 \mathrm{nmol} / \mathrm{mL}$. The level of TBARS in the plasma of tannery workers was significantly higher than that of the healthy controls as shown in Figure 4.

Out of the total study subjects, the mean level of TBARS in the plasma of individuals having both the alleles for GSTM1

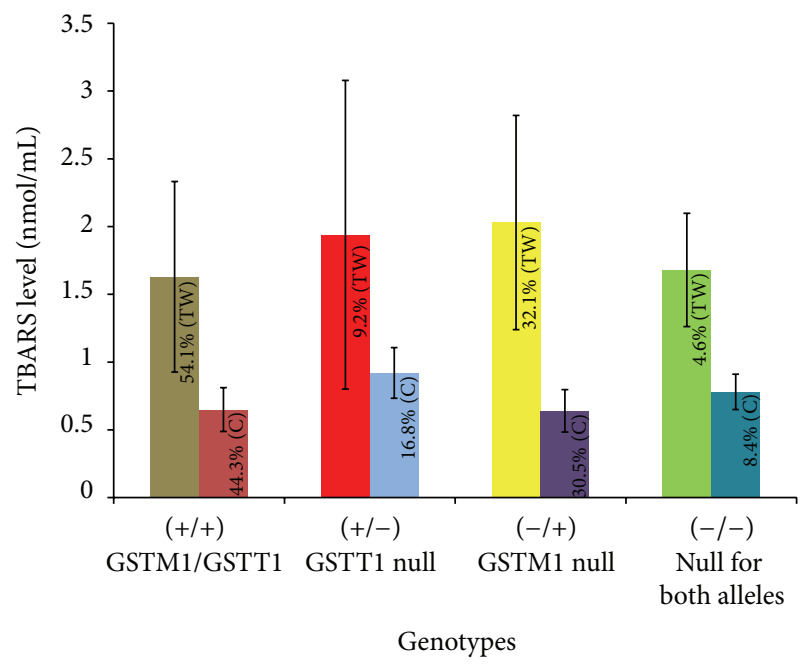

FIgURE 5: Distribution of TBARS in the plasma of different genotypes of tannery workers (TW) and healthy controls (C). The levels of TBARS in the plasma of all genotypes of tannery workers were found higher than that of the healthy controls. The bars represent the standard deviation of TBARS values of each genotype and the TBARS values (expressed as $\mathrm{nmol} / \mathrm{mL}$ ) were calculated from the average of two independent experiments for each sample. Values within the bar represent the percentages of respective genotypes in the studied population.

and GSTT1 genes was $1.63 \pm 0.7 \mathrm{nmol} / \mathrm{mL}$ while, in case of individuals having GSTM1 alleles with null alleles of GSTT1 gene and in individuals having GSTT1 alleles with null alleles of GSTM1, the mean levels of plasma TBARS were measured to be $1.59 \pm 1.16$ and $1.33 \pm 1.01 \mathrm{nmol} / \mathrm{mL}$, respectively. Tannery workers having both alleles for GSTM1 and GSTT1 genes had statistically significantly higher levels of TBARS $(1.63 \pm$ $0.7 \mathrm{nmol} / \mathrm{mL})$ in their plasma $(p<0.001)$ compared to the mean level of the healthy controls $(0.65 \pm 0.62 \mathrm{nmol} / \mathrm{mL})$. On the other hand, the plasma level of TBARS in the working individuals having GSTM1 alleles with null alleles of GSTT1 gene was $1.59 \pm 1.16 \mathrm{nmol} / \mathrm{mL}$, while in their healthy counterparts the mean level was $0.92 \pm 0.87 \mathrm{nmol} / \mathrm{mL}$. Also, the level of TBARS in the plasma of tannery workers having only alleles for GSTM1 gene was $2.03 \pm 0.8 \mathrm{nmol} / \mathrm{mL}$ compared to the level present in their healthy counterparts $(0.64 \pm$ $0.56 \mathrm{nmol} / \mathrm{mL}$ ). It was found that the mean levels of plasma TBARS in these groups of heterozygous tannery workers were significantly higher than those of the control subjects. Moreover, the mean levels of TBARS in the plasma of the tannery workers and healthy controls having null alleles for both GSTM1 and GSTT1 genes were $1.68 \pm 0.42 \mathrm{nmol} / \mathrm{mL}$ and $0.78 \pm 0.08 \mathrm{nmol} / \mathrm{mL}$, respectively (Figure 5).

\section{Discussion}

GSTM1 is one of the most key subclasses of GSTs, which has potent protective role against cancer compared to other GST subtypes [26-29]. Null GSTM1 genotypes have been demonstrated to be most commonly associated with risk of cancers. In addition, McLellan et al. described a rapid GST 
activity in Saudi Arabian individuals which was attributed to a tandem M1 gene duplication resulting in two functional M1 genes [30] and, thus, it was inferred that this rapid detoxification phenotype could have an increased protective effect against carcinogens. Further, GSTT1 is involved in the bioactivation of carcinogens [31]. Recent evidence has shown that tannery workers are more prone to genotoxicity and increased risk of oxidative stress [32]. Individual variations in GSTT1 and GSTM1 genotypes have been demonstrated to modulate the extent of genotoxicity in tannery workers [33]. This study determined the genotypic distribution of glutathione S-transferase (GST) M1 and T1 genes in Bangladeshi tannery workers and healthy controls along with the status of oxidative stress and total activity of GST enzymes in different genotypes.

Of the total population considered in the present study, half of them were heterozygous with regard to GSTM1 and GSTT1 alleles while only $12.2 \%$ were GSTT1 null genotypes and one-third of the population were GSTM1 null genotypes. Similar prevalence of GSTT1 null genotype was reported in Caucasians $[34,35]$. Among the world population, the distributions of GSTT1 null genotypes were found to be 47.7\% in Caucasians [36], 55-80\% in Asians [37, 38], 27\% in Eastern and Southern Africans [10], 28-35\% in African Americans [26], 22\% in Nigerians [27], and 32.4\% in Indians [28]. On the other hand, the distribution of GSTT1 null genotypes was found to be lower in our population which has also been reflected in other ethnic groups like $16.7 \%$ in Caucasians [36], 24.9\% in Blacks [29], and 16.2\% in Indians [28]. However, other studies demonstrated that $41 \%$ of the Asians have GSTT1 null genotypes [39, 40]. Moreover, the distribution of GSTM1 null genotypes was almost even in the healthy controls and tannery workers as shown in Table 2 which was found to be lower compared to that of the Chinese healthy population reported by Setiawan et al. [41]. Stratification of the genotypes between tannery workers and healthy controls revealed that the null GSTT1 genotypes were higher in tannery workers (16.8\%) compared to those of the healthy controls (9.2\%). In contrast, the frequency of the GSTT1 gene deletions (null GSTT1 genotypes) in healthy Koreans was almost five times higher [42].

Individuals with homozygous deletions for both GSTM1 and GSTT1 genes (double null genotypes) may contribute to the increased risk for malignancies as a consequence of a decreased efficiency to detoxify possible carcinogens. The occurrences of double null genotypes vary among different ethnic groups. In the present study, the frequency of double null genotype (-/-) was higher in the tannery workers than that of the healthy controls. Considering these facts, though $50 \%$ of the total population had both GSTM1 and GSTT1 alleles, rest of them are at risk of genotoxicity and oxidative stress due to the absence of xenobiotics detoxifying GSTM1 and/or GSTT1 alleles.

The GST activity is a parameter for identifying tissue damage and neoplasia [43]. This study further reports varied GST activities in different genotypes. The activity was found higher in individuals having both the alleles for GSTM1 and GSTT1 genes. On the other hand, GST activity was found lower in individuals having either GSTM1 or GSTT1 null genotypes $(+/-,-/+)$ indicating the role of these genotypes in regulating GST activity. Interestingly, GST activity was also found higher in individuals with null alleles for both the GSTM1 and GSTT1 genes. To cope with the oxidative stress, the individuals even with the lowest percentages of double negative alleles (-/-) showed higher GST activity which might be due to expression of other isoenzymes (e.g., GSTP1, GST Alpha, GST delta, GST kappa, GST Omega, and GST Zeta). TBARS are formed as a product of lipid peroxidation due to oxidative stress. Higher TBARS level indicates lower capacity to detoxify reactive oxygen species [44]. It was observed that not only was the TBARS level found to be significantly higher in the plasma of the tannery workers (Figure 4) but also the mean levels of plasma TBARS in all genotypes of tannery workers were higher than those of the healthy controls (as shown in Figure 5). To verify the effect of other factors in regulating GST or TBARS levels we categorized our data according to the smoking status. Although the percentages of smokers were higher in tannery workers compared to those of healthy controls, the average GST activity as well as the levels of TBARS between the smokers and nonsmokers within the tannery workers did not vary significantly. However, due to smaller number of samples, distribution of these values in different GSTM1 and GSTT1 genotypes has not been presented to compare between smokers and nonsmokers.

This study revealed that the genotypic variations with regard to GSTM1 and GSTT1 genes were distributed among the study subjects with different frequencies and there were no significant differences in various genotypes of GSTM1 and GSTT1 gene polymorphisms between tannery workers and healthy controls. GST activity varied among different genotypes while the rate of lipid peroxidation in tannery workers was significantly higher than that of healthy controls irrespective of their different genotypes and this indicated that the tannery workers are at high risk of oxidative damage. Moreover, grouping of tannery workers in different risk groups based on the GST activity (in addition to GSTM1 and GSTT1 genotypes) might enable us to develop a model of regular health screening for the individuals working in this toxic environment. However, more studies with higher number of participants are warranted to establish the frequency distribution of genes for other GST isoenzymes. In summary, only GSTM1 and GSTT1 alleles may not be the sole contributor to GST activity thereby instigating the importance of future studies in this area.

\section{Competing Interests}

The authors declare that they have no competing interests.

\section{Authors' Contributions}

A. H. M. Nurun Nabi conceived the idea of the research work. Under the supervision of A. H. M. Nurun Nabi, Jobaida Akther carried out all of the work. Mahmud Hossain, Md. Ismail Hosen, Akio Ebihara, and Tsutomu Nakagawa helped designing primers and resolving proper PCR reaction. A. H. 
M. Nurun Nabi, Laila N. Islam, and Fumiaki Suzuki together prepared the paper. All authors read and approved the final paper.

\section{Acknowledgments}

This study was supported by the grant provided by Ministry of Science and Technology, Government of the People's Republic of Bangladesh, in the fiscal year of 2013-2014. The authors also acknowledge their participants who understood the need of the study and willingly donated their blood. This work was also partly supported by the United Graduate School of Agricultural Sciences, Gifu University, Japan.

\section{References}

[1] P. D. Josephy, "Genetic variations in human glutathione transferase enzymes: significance for pharmacology and toxicology," Human Genomics and Proteomics, vol. 13, Article ID 876940, 2010.

[2] J. D. Hayes, J. U. Flanagan, and I. R. Jowsey, "Glutathione transferases," Annual Review of Pharmacology and Toxicology, vol. 45, pp. 51-88, 2005.

[3] B. Mannervik, P. G. Board, J. D. Hayes, I. Listowsky, and W. R. Pearson, "Nomenclature for mammalian soluble glutathione transferases," Methods in Enzymology, vol. 401, pp. 1-8, 2005.

[4] J. Seidegard, W. R. Vorachek, R. W. Pero, and W. R. Pearson, "Hereditary differences in the expression of the human glutathione transferase active on trans-stilbene oxide are due to a gene deletion," Proceedings of the National Academy of Sciences of the United States of America, vol. 85, no. 19, pp. 7293-7297, 1988.

[5] S. Anttila, A. Hirvonen, H. Vainio, K. Husgafvel-Pursiainen, J. D. Hayes, and B. Ketterer, "Immunohistochemical localization of glutathione S-transferases in human lung," Cancer Research, vol. 53, no. 23, pp. 5643-5648, 1993.

[6] J. Brockmöller, R. Kerb, N. Drakoulis, B. Staffeldt, and I. Roots, "Glutathione S-transferase M1 and its variants A and B as host factors of bladder cancer susceptibility: a case-control study," Cancer Research, vol. 54, no. 15, pp. 4103-4111, 1994.

[7] A. H. M. Heagerty, D. Fitzgerald, A. Smith et al., "Glutathione S-transferase GSTM1 phenotypes and protection against cutaneous tumours," The Lancet, vol. 343, no. 8892, pp. 266-268, 1994.

[8] M. C. Wilce, P. G. Board, S. C. Feil, and M. W. Parker, "Crystal structure of both $\theta$ and $\mu$ GSTs but data here reported do not suggest of a theta-class glutathione transferase," The EMBO Journal, vol. 14, pp. 2133-2143, 1995.

[9] J. H. T. M. Ploemen, A. Van Schanke, B. Van Ommen, and P. J. Van Bladeren, "Reversible conjugation of ethacrynic acid with glutathione and human glutathione S-transferase P1-1," Cancer Research, vol. 54, no. 4, pp. 915-919, 1994.

[10] C. Dandara, J. Sayi, C. M. Masimirembwa et al., "Genetic polymorphism of cytochrome P450 1A1 (Cyp1A1) and glutathione transferases (M1, T1 and P1) among Africans," Clinical Chemistry and Laboratory Medicine, vol. 40, no. 9, pp. 952-957, 2002.

[11] Y.-L. Lee, T.-R. Hsiue, Y.-C. Lee, Y.-C. Lin, and Y. L. Guo, “The association between glutathione S-transferase P1, M1 polymorphisms and asthma in Taiwanese schoolchildren," Chest, vol. 128, no. 3, pp. 1156-1162, 2005.
[12] H. H. Nelson, J. K. Wiencke, D. C. Christiani et al., "Ethnic differences in the prevalence of the homozygous deleted genotype of glutathione S-transferase theta," Carcinogenesis, vol. 16, no. 5, pp. 1243-1246, 1995.

[13] Z. Trizna, G. L. Clayman, M. R. Spitz, K. L. Briggs, and H. Goepfert, "Glutathione S-transferase genotypes as risk factors for head and neck cancer," The American Journal of Surgery, vol. 170, no. 5, pp. 499-501, 1995.

[14] G. Chenevix-Trench, J. Young, M. Coggan, and P. Board, "Glutathione S-transferase $\mathrm{ml}$ and tl polymorphisms: susceptibility to colon cancer and age of onset," Carcinogenesis, vol. 16, no. 7, pp. 1655-1657, 1995.

[15] Z. Mikoczy and L. Hagmar, "Cancer incidence in the Swedish leather tanning industry: updated findings 1958-99," Оссираtional and Environmental Medicine, vol. 62, no. 7, pp. 461-464, 2005.

[16] M. G. Medeiros, A. S. Rodrigues, M. C. Batoréu, A. Laires, J. Rueff, and A. Zhitkovich, "Elevated levels of DNA-protein crosslinks and micronuclei in peripheral lymphocytes of tannery workers exposed to trivalent chromium," Mutagenesis, vol. 18, no. 1, pp. 19-24, 2003.

[17] S. J. S. Flora, M. Mittal, and A. Mehta, "Heavy metal induced oxidative stress \& its possible reversal by chelation therapy," Indian Journal of Medical Research, vol. 128, no. 4, pp. 501-523, 2008.

[18] K. K. Abu-Amero, O. M. Al-Boudari, G. H. Mohamed, and N. Dzimiri, " $\mathrm{T}^{\text {null }}$ and $\mathrm{M}^{\text {null }}$ genotypes of the glutathione S-transferase gene are risk factor for CAD independent of smoking," BMC Medical Genetics, vol. 7, article 38, 2006.

[19] M. Habdous, G. Siest, B. Herbeth, M. Vincent-Viry, and S. Visvikis, "Glutathione S-transferases genetic polymorphisms and human diseases: overview of epidemiological studies," Annales de Biologie Clinique, vol. 62, no. 1, pp. 15-24, 2004.

[20] R. C. Strange, M. A. Spiteri, S. Ramachandran, and A. A. Fryer, "Glutathione-S-transferase family of enzymes," Mutation Research/Fundamental and Molecular Mechanisms of Mutagenesis, vol. 482, no. 1-2, pp. 21-26, 2001.

[21] Y. Sekine, S. Hommura, and S. Harada, "Frequency of glutathione-S-transferase 1 gene deletion and its possible correlation with cataract formation," Experimental Eye Research, vol. 60, no. 2, pp. 159-163, 1995.

[22] O. Oz, N. Aras Ates, L. Tamer, O. Yildirim, and U. Adigüzel, "Glutathione S-transferase M1, T1, and P1 gene polymorphism in exudative age-related macular degeneration: a preliminary report," European Journal of Ophthalmology, vol. 16, no. 1, pp. 105-110, 2006.

[23] R. Afruza, L. N. Islam, S. Banerjee, M. M. Hassan, F. Suzuki, and A. N. Nabi, "Renin gene polymorphisms in bangladeshi hypertensive population," Journal of Genomics, vol. 2, pp. 45-53, 2014.

[24] B. Mannervik and C. Guthenberg, "Glutathione transferase (human placenta)," Methods in Enzymology, vol. 77, pp. 231-235, 1981.

[25] K. Yagi, "Simple procedure for specific assay of lipid hydroperoxides in serum or plasma," Free Radical Formation and Antioxidant Protection, vol. 108, pp. 101-106, 1998.

[26] C.-L. Chen, Q. Liu, and M. V. Relling, "Simultaneous characterization of glutathione S-transferase M1 and T1 polymorphisms by polymerase chain reaction in American whites and blacks," Pharmacogenetics, vol. 6, no. 2, pp. 187-191, 1996.

[27] L. Zhao, J. Alldersen, A. Fryer et al., "Polymorphism at the glutathione S-transferase GSTM1 locus: a study of the frequencies 
of the GSTM1 A, B, A/B and null phenotypes in Nigerians," Clinica Chimica Acta, vol. 225, no. 1, pp. 85-88, 1994.

[28] S. Singh, V. Kumar, S. Thakur et al., "Genetic polymorphism of glutathione S-transferase M1 and T1 in Delhi population of Northern India," Environmental Toxicology and Pharmacology, vol. 28, no. 1, pp. 25-29, 2009.

[29] N. A. Lavender, M. L. Benford, T. T. VanCleave et al., "Examination of polymorphic glutathione S-transferase (GST) genes, tobacco smoking and prostate cancer risk among men of African descent: a case-control study," BMC Cancer, vol. 9, article 397, 2009.

[30] R. A. McLellan, M. Oscarson, A. K. Alexandrie et al., "Characterization of a human glutathione S-transferase mu cluster containing a duplicated GSTM1 gene that causes ultrarapid enzyme activity," Molecular Pharmacology, vol. 52, no. 6, pp. 958-965, 1997.

[31] B. U. Ebeshi, O. O. Bolaji, and C. M. Masimirembwa, "Glutathione- $S$-transferase (M1 and T1) polymorphisms in Nigerian populations," Journal of Medical Genetics and Genomics, vol. 3, no. 4, pp. 56-60, 2011.

[32] K. Ambreen, F. H. Khan, S. Bhadauria, and S. Kumar, "Genotoxicity and oxidative stress in chromium-exposed tannery workers in North India," Toxicology and Industrial Health, vol. 30, no. 5, pp. 405-414, 2014.

[33] K. Kvitko, E. Bandinelli, J. A. P. Henriques et al., "Susceptibility to DNA damage in workers occupationally exposed to pesticides, to tannery chemicals and to coal dust during mining," Genetics and Molecular Biology, vol. 35, no. 4, pp. 1060-1068, 2012.

[34] M. Deakin, J. Elder, C. Hendrickse, D. Peckham, D. Baldwin, and C. Pantin, "Short communication: glutathione S-transferase GSTT1 genotypes and susceptibility to cancer: studies of interactions with GSTM1 in lung, oral, gastric and colorectal cancers," Carcinogenesis, vol. 17, no. 4, pp. 881-884, 1996.

[35] N. Jourenkova, M. Reinikanen, C. Bouchardy et al., "Effects of glutathione S-transferases GSTM1 and GSTT1 genotypes on lung cancer risk in smokers," Pharmacogenetics, vol. 7, no. 6, pp. 515-518, 1997.

[36] M. A. Amer, M. H. Ghattas, D. M. Abo-Elmatty, and S. H. Abou-El-Ela, "Influence of glutathione S-transferase polymorphisms on type-2 diabetes mellitus risk," Genetics and Molecular Research, vol. 10, no. 4, pp. 3722-3730, 2011.

[37] T. R. Rebbeck, A. H. Walker, J. M. Jaffe, D. L. White, A. J. Wein, and S. B. Malkowicz, "Glutathione S-transferase- $\mu$ (GSTMI) and 0 (GSTT19) genotype in the ethiology of prostate cancer," Cancer Epidemiology, Biomarkers \& Prevention, vol. 8, pp. 283287, 1999.

[38] R. Lai, L. Crevier, and L. Thabane, "Genetic polymorphisms of glutathione $S$-transferases and the risk of adult brain tumors: a meta-analysis," Cancer Epidemiology Biomarkers and Prevention, vol. 14, no. 7, pp. 1784-1790, 2005.

[39] B. Kíran, M. Karkucak, H. Ozan et al., "GST (GSTM1, GSTT1, and GSTP1) polymorphisms in the genetic susceptibility of Turkish patients to cervical cancer," Journal of Gynecologic Oncology, vol. 21, no. 3, pp. 169-173, 2010.

[40] R. Amtha, C. S. Ching, R. Zain et al., "GSTM1, GSTT1 and CYP1A1 polymorphisms and risk of oral cancer: a case-control study in Jakarta, Indonesia," Asian Pacific Journal of Cancer Prevention, vol. 10, no. 1, pp. 21-26, 2009.

[41] V. W. Setiawan, Z.-F. Zhang, G.-P. Yu et al., "GSTT1 and GSTM1 null genotypes and the risk of gastric cancer: a case- control study in a Chinese population," Cancer Epidemiology Biomarkers and Prevention, vol. 9, no. 1, pp. 73-80, 2000.

[42] K. A. Lee, S. H. Kim, H. Y. Woo, Y. J. Hong, and H. C. Cho, "Increased frequencies of glutathione S-transferase (GSTM1 and GSTT1) gene deletions in Korean patients with acquired aplastic anemia," Blood, vol. 98, no. 12, pp. 3483-3485, 2001.

[43] C. Ntais, A. Polzcarpou, and J. P. Ioannidis, "Association of GSTM1, GSTT1 and GSTP1 gene polzmorphisms with the risk of prostate cancer: a meta-analysis," Cancer Epidemiology, Biomarkers \& Prevention, vol. 14, pp. 176-184, 2005.

[44] J. Lipińska, S. Lipińska, J. Stańczyk et al., "Reactive oxygen species and serum antioxidant defense in juvenile idiopathic arthritis," Clinical Rheumatology, vol. 34, no. 3, pp. 451-456, 2015. 

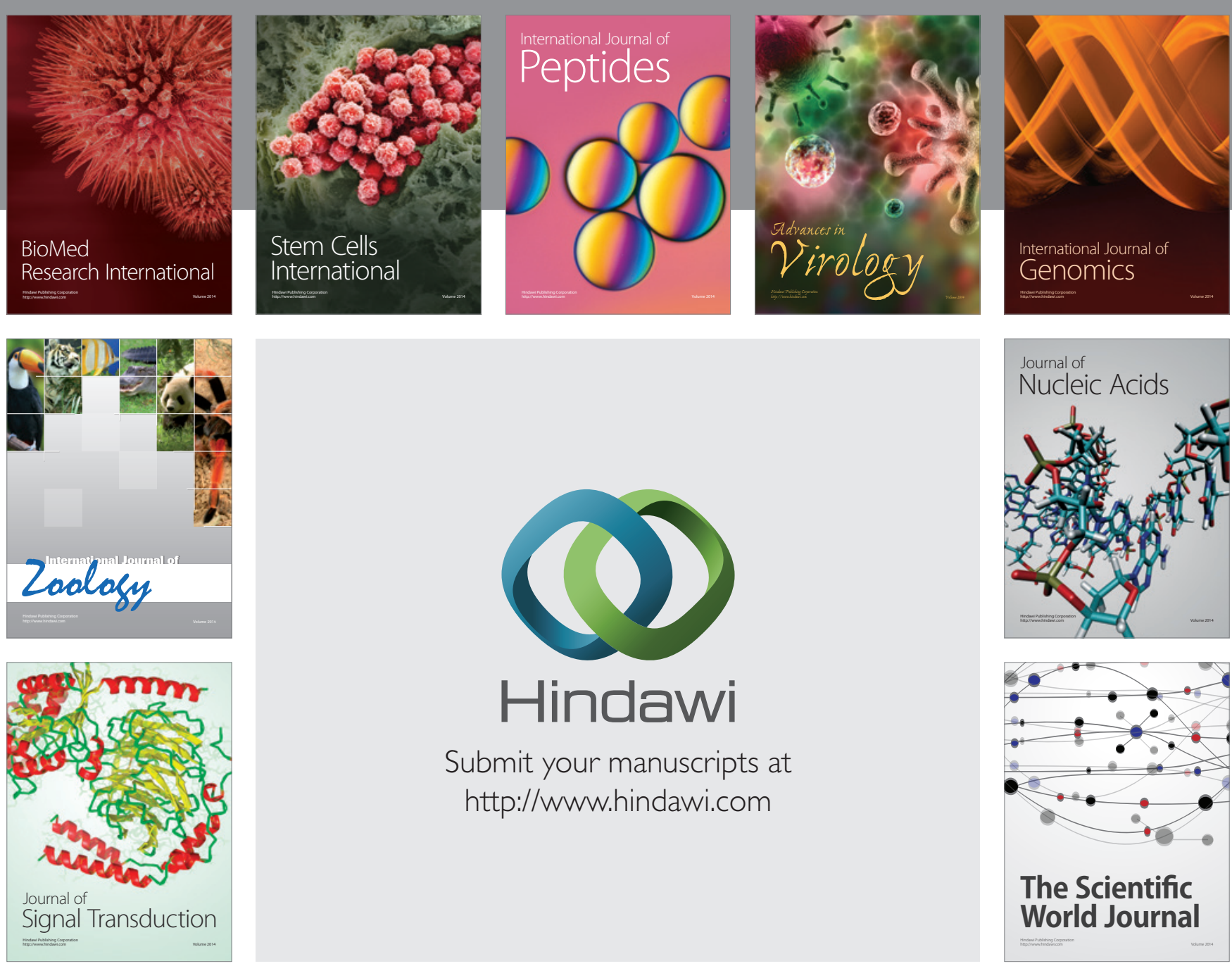

Submit your manuscripts at

http://www.hindawi.com
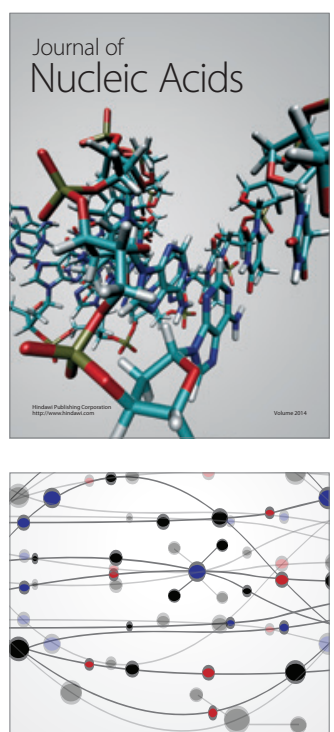

The Scientific World Journal
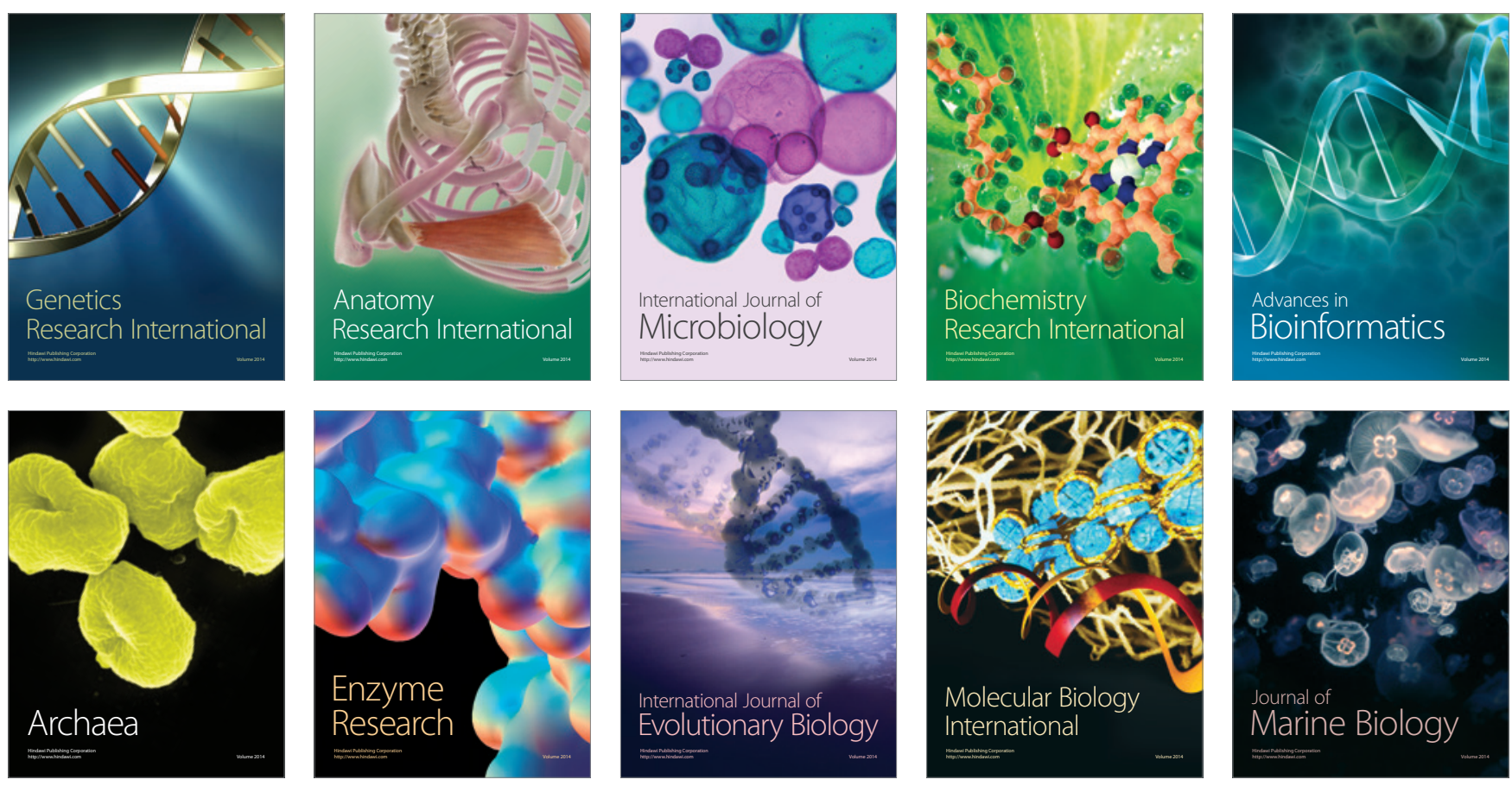